\title{
Production of glucose from oil palm trunk and sawdust of rubberwood and mixed hardwood
}

\begin{abstract}
Disposing of solid waste and demand of fossil fuel have become the great challenges in the 21 st century. Malaysia as one of the top producers of palm oil and wooden furniture in the world is well positioned to take the challenge of the reuses of its enormous output of lignocellulosic biomass such as oil palm trunk, sawdust of rubberwood and sawdust of mixed hardwood generated from palm oil and furniture industries. Before these lignocellulosic biomasses can be used to produce fuel and major chemicals which are normally derived from petroleum, lignocellulosic materials have to be converted to glucose. Hence, it is a need to investigate the conversion efficiency and to determine the optimum conditions for the conversion of lignocellulosic materials to glucose. This present work is aimed to investigate the potential use of oil palm trunk, rubberwood sawdust and mixed hardwood sawdust as an alternative feedstock for lignocellulosic glucose production. This research also served to identify the optimum two-stage concentrated acid hydrolysis condition that can convert these three lignocellulosic biomasses to glucose efficiently. Two stages concentrated sulfuric acid hydrolysis process using different acid concentration and reaction time were performed on those lignocellulosic biomass samples. The optimum results for oil palm trunk, rubberwood and mixed hardwood sawdust were obtained by using $60 \%$ acid concentration reacted for 30 min during 1st stage hydrolysis and subsequently followed by another 60 min reaction time with $30 \%$ acid concentration during the 2 nd stage hydrolysis. The results, showed that oil palm trunk has a higher glucose conversion yield than those of rubberwood sawdust and mixed hardwood sawdust.
\end{abstract}

Keyword: Oil palm trunk; Rubberwood; Mixed hardwood; Concentrated acid hydrolysis; Glucose yield 